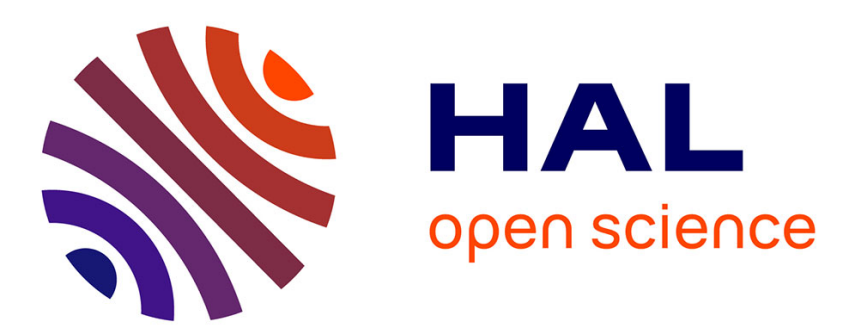

\title{
A critical geometry for lasers with internal lenslike effects
}

\author{
A. Le Floch, J.M. Lenormarid, R. Le Naour, J.P. Taché
}

\section{To cite this version:}

A. Le Floch, J.M. Lenormarid, R. Le Naour, J.P. Taché. A critical geometry for lasers with internal lenslike effects. Journal de Physique Lettres, 1982, 43 (14), pp.493-498. 10.1051/jphyslet:019820043014049300 . jpa-00232081

\section{HAL Id: jpa-00232081 https://hal.science/jpa-00232081}

Submitted on 1 Jan 1982

HAL is a multi-disciplinary open access archive for the deposit and dissemination of scientific research documents, whether they are published or not. The documents may come from teaching and research institutions in France or abroad, or from public or private research centers.
L'archive ouverte pluridisciplinaire HAL, est destinée au dépôt et à la diffusion de documents scientifiques de niveau recherche, publiés ou non, émanant des établissements d'enseignement et de recherche français ou étrangers, des laboratoires publics ou privés. 


\title{
LE JOURNAL DE PHYSIQUE-LETTRES
}

J. Physique - LETTRES 43 (1982) L-493 - L-498

15 JUILLET'1982, PAGE L- 493

Classification

Physics Abstracts

$42.55 \mathrm{~F}-42.60 \mathrm{H}-42.60 \mathrm{D}$

\section{A critical geometry for lasers with internal lenslike effects}

\author{
A. Le Floch (*), J. M. Lenormand (*), R. Le Naour (**) and J. P. Taché $\left(^{*}\right)$ \\ (*) Laboratoire d'Electronique Quantique, Université de Rennes, F-35042 Rennes, France \\ (**) Laboratoire d'Electronique Quantique, Université de Nantes, F-44072 Nantes, France
}

(Reçu le 23 mars 1982, accepté le 18 mai 1982)

\begin{abstract}
Résumé. - Nous signalons une propriété intéressante concernant l'évolution de la taille d'un mode Gaussien lorsqu'une lentille mince ou une lentille induite répartie est insérée dans une cavité laser. $\mathrm{Si}$ on allonge une cavité Fabry-Perot plan concave contenant une lentille placée à mi-distance des miroirs, les variations de taille de mode sur le miroir concave s'annulent pour $d_{\mathrm{c}} \cong 4 R / 5$ et changent de signe pour $d \geqq d_{\mathrm{c}}, R$ étant le rayon de courbure du miroir concave. Cette propriété explique simplement les dissymétries opposées observables sur le Lamb dip, les pics d'absorption saturée et les résonances de la spectroscopie d'absorption intracavité. La vérification expérimentale est faite sur le Lamb dip à $3,39 \mu \mathrm{m}$ grâce à la spectroscopie du diffracté.
\end{abstract}

\begin{abstract}
We point out here an interesting property concerning Gaussian mode size evolution when a thin lens or induced lenslike effects are inserted in a laser cavity. When the distance $d$ between mirrors of a half-symmetric Fabry-Perot with a lens at half-length is changed, the variations of the mode size at the curved mirror cancel for $d_{\mathrm{c}} \cong 4 R / 5$, and change sign when $d \geqq d_{\mathrm{c}}$ (where $R$ is the mirror curvature radius). This property explains simply opposite asymmetries observable on Lamb dips, saturated absorption peaks, and intracavity absorption spectroscopy resonances. The experimental verification is performed on the Lamb dip at $3.39 \mu \mathrm{m}$ by diffracted light spectroscopy.
\end{abstract}

We have already shown that in a laser the diffracted light spectroscopy leads to the physical origin of the Lamb dip asymmetry [1]. With this differential method one can indeed detect with precision mode volume variations due for instance to Gaussian beam saturation of the refractive index. The related nonlinear frequency-dependent diffraction effect appears also in most experiments performed with intracavity Gaussian beams, in saturated absorption used for optical standards and in intracavity absorption spectroscopy. In this paper, we analyse a basic resonator property i.e. the sign of spot size variations of a Gaussian beam with real thin lens or induced lenslike effects inside a laser cavity. In particular, we point out the existence of an interesting geometry labelled hereafter as "critical » which leads to an invariant spot size on the curved 
mirror in the case of a half-symmetric cavity for example. For a distance $d$ between mirrors smaller than a critical length $d_{\mathrm{c}}$, the sign of the spot size variations is identical all along the laser axis and related to the lens sign, while for $d$ greater than $d_{\mathrm{c}}$ the variations are of opposite signs at the two ends of the cavity. The position of the diffracting aperture, indispensable for TEM $_{00}$ mono- $^{-}$ mode oscillation, imposes then the nonlinear resonance asymmetry. For the 0.55 torr pressure considered here these effects are important in comparison to the other causes of resonance asymmetries [2] but vanish at the « critical geometry ».

This " critical length " can be found very simply by introducing a thin lens at half-distance between mirrors of a half-symmetric cavity as shown in figure 1 , where $w_{1}$ and $w_{2}$ represent the radius of the Gaussian mode at $e^{-2}$ intensity. Any wave with a Gaussian transverse distribution may be written as :

$$
E(x, y)=\sqrt{\frac{2}{\pi}} \frac{1}{w} \exp \left(-j \frac{\pi}{\lambda} \frac{x^{2}+y^{2}}{q}\right),
$$

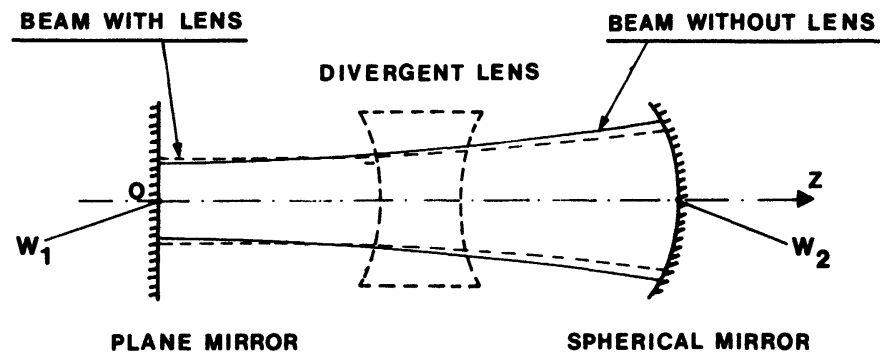

Fig. 1. - Optical cavity with internal diverging lens.

where a complex radius of curvature $q$ is introduced, given by :

$$
\frac{1}{q}=\frac{1}{\rho}-j \frac{\lambda}{\pi w^{2}}
$$

Here $\rho$ is the radius of curvature of the beam and $w$ the spot size at point $z$. As shown by Kogelnik [3], the $q$ parameter allows to describe the evolution of Gaussian modes with the $A B C D$ matrix of the classical ray transformation. If $q_{1}$ and $q_{2}$ describe the Gaussian beam at points 1 and 2 respectively we can write :

$$
q_{2}=\frac{A q_{1}+B}{C q_{1}+D}
$$

The matrix corresponding to propagation along the $z$ axis of figure 1 for a cavity with mirrors of curvature radius $R_{1}$ and $R_{2}$ and a lens of focal length $f$ is such as :

$$
\left(\begin{array}{ll}
A & B \\
C & D
\end{array}\right)=\left(\begin{array}{rr}
1 & 0 \\
-\frac{1}{R_{2}} & 1
\end{array}\right)\left(\begin{array}{ll}
1 & \frac{d}{2} \\
0 & 1
\end{array}\right)\left(\begin{array}{rr}
1 & 0 \\
-\frac{1}{f} & 1
\end{array}\right)\left(\begin{array}{ll}
1 & \frac{d}{2} \\
0 & 1
\end{array}\right)\left(\begin{array}{rr}
1 & 0 \\
-\frac{1}{R_{1}} & 1
\end{array}\right) \text {, }
$$


where :

$$
\begin{aligned}
& A=1-d\left(\frac{1}{R_{1}}+\frac{1}{2 f}\right)+\frac{d^{2}}{4 f R_{1}}, \\
& B=d-\frac{d^{2}}{4 f} \\
& C=-\frac{1}{R_{1}}-\frac{1}{f}-\frac{1}{R_{2}}+d\left[\frac{1}{R_{2}}\left(\frac{1}{R_{1}}+\frac{1}{2 f}\right)+\frac{1}{2 f R_{1}}\right]-\frac{d^{2}}{4 f R_{1} R_{2}}, \\
& D=1-d\left(\frac{1}{2 f}+\frac{1}{R_{2}}\right)+\frac{d^{2}}{4 f R_{2}} .
\end{aligned}
$$

Postulating the self-consistency of the $q$ parameter after a round trip and separating real and imaginary parts, we obtain for the spot sizes on the mirrors [3]

$$
w_{1 f}^{4}=-\left(\frac{\lambda}{\pi}\right)^{2} \frac{B D}{A C} \text { and } w_{2 f}^{4}=-\left(\frac{\lambda}{\pi}\right)^{2} \frac{B A}{D C} .
$$

The usual spot sizes for the empty cavity, noted $w_{1}$ and $w_{2}$, are given by

and

$$
w_{1}^{4}=\left(\frac{\lambda}{\pi}\right)^{2} \frac{d\left(R_{2}-d\right) R_{1}^{2}}{\left(R_{1}-d\right)\left(R_{1}+R_{2}-d\right)}
$$

$$
w_{2}^{4}=\left(\frac{\lambda}{\pi}\right)^{2} \frac{d\left(R_{1}-d\right) R_{2}^{2}}{\left(R_{2}-d\right)\left(R_{1}+R_{2}-d\right)} .
$$

The variations $\frac{\Delta w_{1}}{w_{1}}=\frac{w_{1 f}-w_{1}}{w_{1}}$ at mirror $R_{1}$ and $\frac{\Delta w_{2}}{w_{2}}=\frac{w_{2 f}-w_{2}}{w_{2}}$ at mirror $R_{2}$ versus the distance $d$ between mirrors are represented by the theoretical curves of figure 2 . For the half-symmetric cavity considered here the $\Delta w_{1} / w_{1}$ variations on the plane mirror $\left(R_{1}=\infty\right)$ show a standard behaviour; for a divergent lens as considered in figure 2 , the spot size increases for all the $d$ values. On the contrary, on the spherically curved mirror, the $\Delta w_{2} / w_{2}$ variations cancel at the "critical length " $d_{\mathrm{c}} \cong \frac{4 R_{2}}{5}$ and change sign at further distance. The equation giving the " critical length » in the elementary case considered here, has a relatively simple analytic expression i.e. :

$$
3 d^{2}-d\left(4 R_{2}+10 f\right)+8 R_{2} f=0 .
$$

For focal lengths $|f| \geqq 30 R_{2}$, we find the $4 R_{2} / 5$ value. At the critical length, the spot size on the spherical mirror is invariant for the low positive or negative convergence values as those considered on figure 2 . With $d$ greater than $d_{\mathrm{c}}$, an increase of the spot size on the plane mirror and a decrease of the spot size on the curved mirror are predicted for a diverging lens for example. Hence with this geometry, there exists a point inside the cavity where the mode variations also cancel. However this point may be located inside the active medium and is not generally useful. The existence of the " critical geometry " leads to the interpretation of resonance asymmetries which are observed in intracavity experiments using Gaussian beams. These mode variations occur indeed when focusing and defocusing are due to induced lenslike effects in atomic or molecular systems. In this case, the lens effect results from a greater saturation of the refractive index of the atomic line on the axis than on the edge of the Gaussian beam. Futhermore we recall that such a 

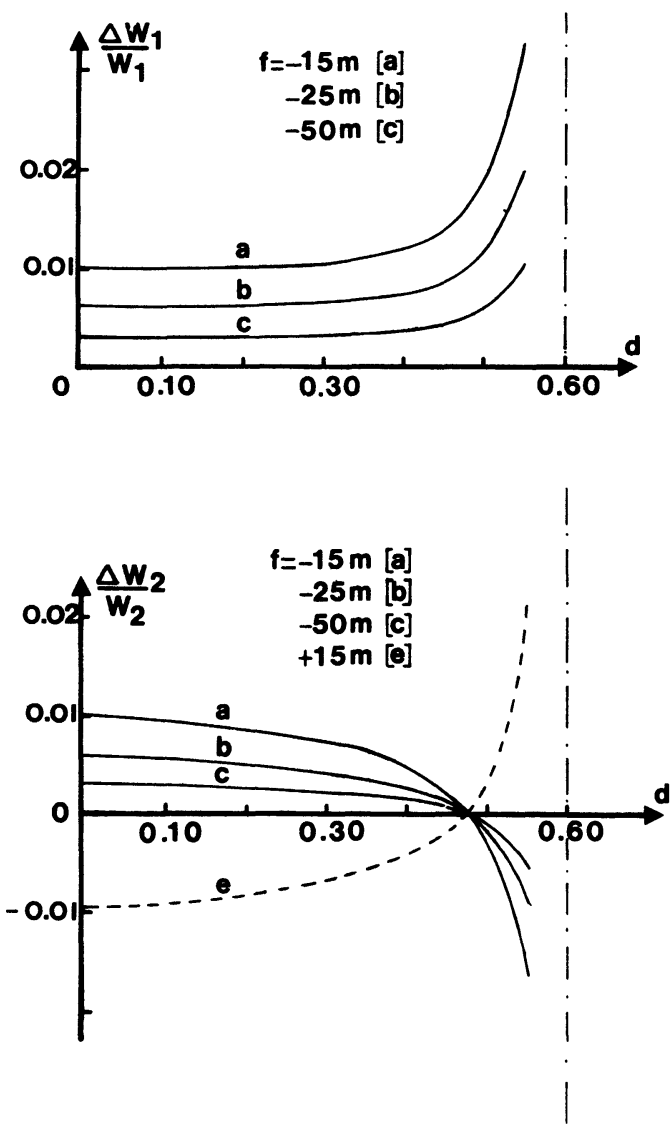

Fig. 2. - Relative variations $\Delta w_{1} / w_{1}$ and $\Delta w_{2} / w_{2}$ of spot sizes at both end mirrors as function of the cavity length for different values of the focal length.

lens will be frequency dependent, leading to frequency dependent mode variations and diffraction losses. Complete calculation of such a lenslike effect is to be published elsewhere [4]. The distributed character of the lens effect does not introduce significant variations of the critical length compared to the thin lens case. However when the emission (or absorption) cell is moved from the centre of the cavity the critical distance is of course modified.

Experimental verification of predicted opposite asymmetries with the localization of the diffracting aperture is performed on the $3.39 \mu \mathrm{m}$ line of a He-Ne laser, for a cavity length greater than the critical value. Furthermore a symmetric profile for the critical geometry is also obtained. We recall that, for the short geometry, $d<d_{\mathrm{c}}$, which corresponds to most of the published results [5], the standard asymmetry is characterized as in reference [1] with a higher intensity on the low frequency side of the Lamb dip, for any position of the aperture. The focusing effect on this side of an emission line corresponds to lower diffraction losses [6] which are detected by the diffraction spectroscopy [1]. Here we use the cavity corresponding to the curves of figure 2, i.e. we use a plane and a $0.60 \mathrm{~m}$ radius curved mirror. The corresponding critical length is thus $d_{\mathrm{c}} \cong 0.48 \mathrm{~m}$. When $d>d_{\mathrm{c}}$, for example for $d \cong 0.57 \mathrm{~m}$, we obtain, when the aperture is located on the plane mirror, the standard asymmetry on the output beam, as on figure 3 , with a blue shift of the Lamb dip centre and the opposite symmetry on the diffracted beam. On the contrary, when we place the aperture at the curved mirror end, the $w_{2}$ variations are of opposite sign com- 

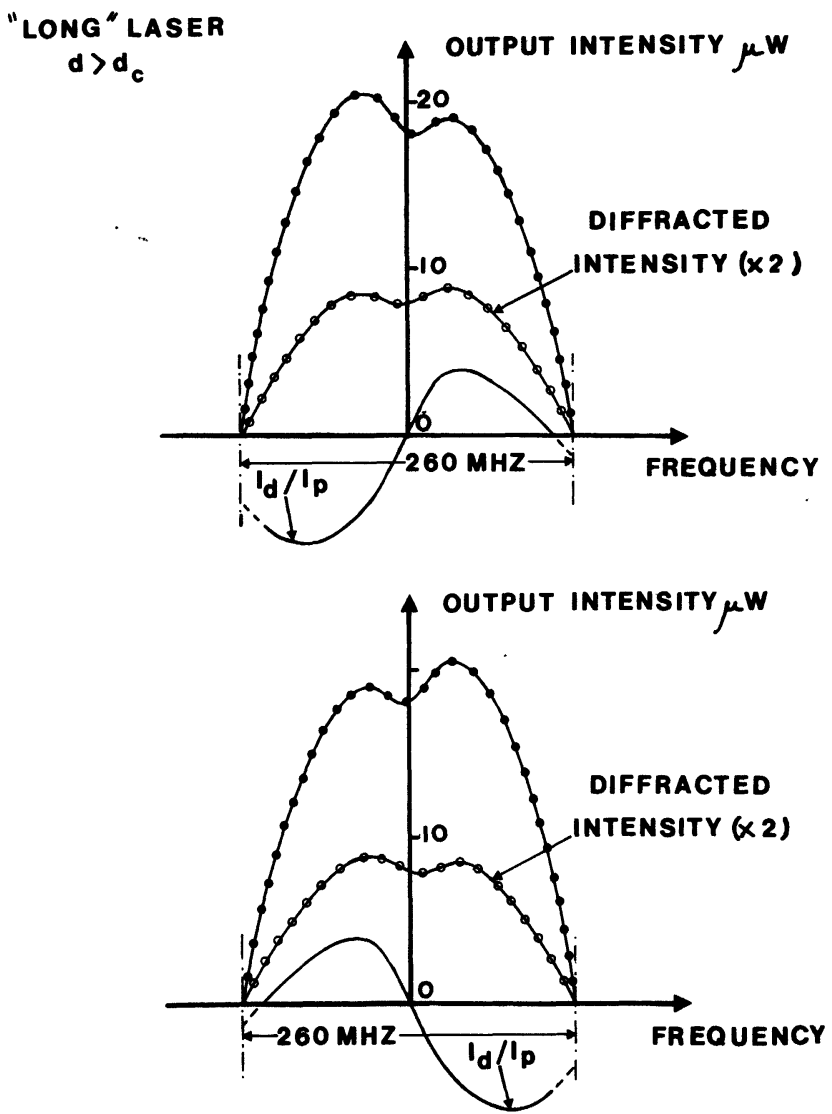

Fig. 3. - Theoretical curves and experimental points of the output laser intensity and of the diffracted light intensity for the aperture located successively on the plane and the curved mirrors. The diffraction losses at the aperture $v s$. frequency are experimental in both cases. The total pressure is 0.55 torr. The distance between mirrors $\left(R_{1}=\infty, R_{2}=0.6 \mathrm{~m}\right)$ is $d=0.57 \mathrm{~m}>d_{\mathrm{c}}$.

pared to those of $w_{1}$ and the asymmetry of the output beam is reversed with a maximum on the high frequency side and a red shift line centre. The diffracted beam spectroscopy confirms these results and shows that, for such a given laser, the losses mechanism is reversed with the localization of the diffracting aperture at one or another cavity end. The normalized losses reported on figure 3 are indeed reversed. The existence of the critical geometry is verified by placing the curved mirror and the aperture at $0.48 \mathrm{~m}$ from the plane mirror (Fig. 4). The two beams then give symmetric profiles without corresponding shifts. All the theoretical curves are drawn by inserting the measured losses in the usual Lamb dip formula used in reference [1].

The critical geometry may be essential for the accuracy of optical standards developed in many laboratories. For each laser locked to a saturated absorption peak, its particular geometry allows to predict a type of asymmetry with a blue or a red shift depending on the sign of mode variation at the limiting aperture. Note also that such effects introduce large asymmetries in intracavity absorption spectroscopy developed by many groups [7] and may be important in high resolution spectroscopy.

This research was partially supported by C.N.R.S. and D.R.E.T. 

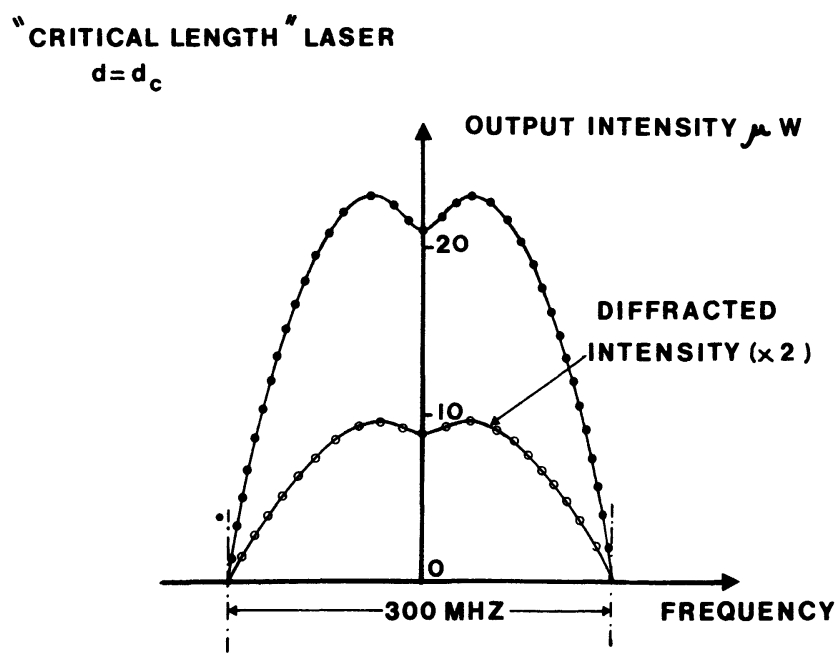

Fig. 4. - Theoretical curves and experimental points of the output laser intensity and of the diffracted light intensity for the " critical geometry " $\left(d=d_{\mathrm{c}} \cong \frac{4}{5} R_{2}=0.48 \mathrm{~m}\right)$. The reflectivities of the plane and curved mirrors are respectively 0.95 and 0.65 .

\section{References}

[1] Le Floch, A., Le Naour, R., Lenormand, J. M. and Taché, J. P., Phys. Rev. Lett. 45 (1980) 544.

[2] Borde, C. J., Camy, G. and Decomps, B., Phys. Rev. A 20 (1979) 254.

[3] Kogelnik, H., Bell. Syst.'Tech. J. 44 (1965) 455 and Appl. Opt. 4 (1965) 1562.

BAUES, P., Opt. Electronics 1 (1969) 37.

[4] Le Floch, A., Lenormand, J. M., Le NaOuR, R., TAché, J. P., to be published and C.N.R.S. Report (1981).

[5] Cordover, R. H. and Bonczyk, P. A., Phys. Rev. 188 (1969) 696.

Barger, R. L. and Hall, J. L., Phys. Rev. Lett. 22 (1969) 4.

Kramer, G., Weiss, C. O. and HelmKe, J., Z. Naturforsch. 30 (1969) 1128.

[6] Fox, A. G. and LI, T., J. Quantum Electron. 12 (1966) 774.

GARSIDE, B. K., I.E.E.E. J. Quantum Electron. 11 (1968) 940.

[7] Hill, W. T., Abreu, R. A., Hansch, T. W. and Schawlow, A. L., Opt. Commun. 32 (1980) 96.

Bray, R. G., Henke, W., Liu, S. K., Reedy, K. V. and Berry, M. J., Chem. Phys. Lett. 47 (1977) 213.

Kumar, P., Brink, G. O., Spence, S. and Lakkaraju, H. S., Opt. Commun. 32 (1980) 129.

HARRIS, S. J. and WeINER, A., Opt. Lett. 6 (1981) 142. 